\title{
Enhancement of Critical Heat Flux in Tight Rod Bundle with Wire Spacer
}

\author{
Dan Tri Le ${ }^{1}$ and Minoru Takahashi ${ }^{2}$ \\ 1. Department of Nuclear Engineering, Tokyo Institute of Technology, Tokyo 152-8550, Japan \\ 2. Laboratory for Advanced Nuclear Energy, Tokyo Institute of Technology, Tokyo 152-8550, Japan
}

Received: December 04, 2015 / Accepted: December 22, 2015 / Published: February 29, 2016.

\begin{abstract}
The experiment of CHF (critical heat flux) was conducted for water boiling two-phase flow in three-pin tight rod bundle. The effects of with and without wire spacers and the pitch to diameter ratio $p / d$ on $\mathrm{CHF}$ were investigated under the conditions of mass flux range $250-430 \mathrm{~kg} /\left(\mathrm{m}^{2} \cdot \mathrm{s}\right)$, inlet temperature from $70{ }^{\circ} \mathrm{C}$ to $92{ }^{\circ} \mathrm{C}$ and the pressure of $0.1 \mathrm{MPa}$. The CHF was enhanced by wire spacers in comparison with the results of CHF without wire spacers. The CHF was enhanced by reducing the $p / d$ from 1.18 to 1.10 under the same flow rate condition, although it did not change appreciably with the change of $p / d$ under the same mass flux condition.
\end{abstract}

Key words: Critical heat flux, tight lattice core, boiling two-phase flow, wire spacer.

\section{Nomenclature}

$\begin{array}{ll}d & \text { Outer diameter of heater pin }(\mathrm{m}) \\ D_{h e} & \text { Heated equivalent diameter }(\mathrm{m}) \\ D_{h y} & \text { Hydraulic diameter }(\mathrm{m}) \\ d_{\text {wire }} & \text { Wire diameter }(\mathrm{m}) \\ G & \text { Mass flux }\left(\mathrm{kg} / \mathrm{m}^{2} \cdot \mathrm{s}\right) \\ H & \text { Axial pitch of wire spacer }(\mathrm{m}) \\ L & \text { Heated length }(\mathrm{m}) \\ P & \text { Pressure }(\mathrm{MPa}) \\ p & \text { Pitch }(\mathrm{m}) \\ q C H F & \text { Critical heat flux }\left(\mathrm{kW} / \mathrm{m}^{2}\right) \\ W & \text { Mass flow rate }(\mathrm{kg} / \mathrm{s}) \\ X & \text { Thermal equilibrium steam quality } \\ Z & \text { Distance from the upstream end of the heater } \\ \text { Abbreviations } & \text { pin to CHF position (m) } \\ \text { CHF } & \text { Critical heat flux } \\ \text { LWR } & \text { Light water reactor } \\ \text { RMWR } & \text { Reduced-moderation water reactor }\end{array}$

\section{Introduction}

Conversion ratio of plutonium is generally lower than unity in thermal neutron reactors such as conventional LWR (light water reactors). However, if

Corresponding author: Dan Tri Le, doctoral student, research field: thermal hydraulic in nuclear reactor. the neutron spectrum is made harder by reducing moderator-to-fuel ratio, that is, a tight lattice core, the conversion ratio can be made nearly unity even in LWRs [1]. Such LWRs can be not only fissile breeder but also actinide transmutator. It has been reported that, the conversion ratio can be higher than unity in tight lattice cores with a pitch-to-diameter ratio, $p / d$, of 1.09 [2] and 1.06 [3].

Coolability is one of the most important issues for the tight lattice core, since flow areas are very narrow. The thermal-hydraulic performance in tight rod bundle with grid spacer has been investigated experimentally for the study of RMWR (reduced-moderation water reactor) [4]. The experimental results showed that, the coolability of the tight lattice core was good under the reasonable flow condition.

CHF (critical heat flux) is the most important feature for the judgment of coolability. CHF behavior in tight rod bundle with grid spacer was investigated experimentally for tight 37-rods bundle using Freon-12 [5] and water [6] as a coolant. The results with Freon-12 showed that, the effects of pressure, mass flux and steam quality on CHF were similar to 
those of data in round tube channel [7]. On the other hand, the results with water cooled type showed that, the effects of flow parameters on CHF were the same with those in 7-rod bundle [8]. The subchannel analysis was performed for the experimental result [9].

The effect of gap width on CHF in tight rod bundle with grid spacer was investigated experimentally for 37-rods bundle [10]. It was found that the CHF values were lower in the channel with a gap width of $1.0 \mathrm{~mm}$ than in the channel with a gap width of $1.3 \mathrm{~mm}$ at the same mass flux.

It can be seen that CHF in tight rod bundle with grid spacer were well investigated, and the effects of mass flux, pressure, steam quality and grid spacer on CHF were made clear experimentally and analytically.

Wire spacers are recommended rather than grid spacers for fuel assemblies in the tight lattice core, in particular, with smaller values of $p / d$ for the breeder type of LWRs. The increase of CHF by wire spacer was found in an experiment for a single fuel pin with and without wire spacer [11]. The CHF values increased up to $25 \%$ by wire spacer compared with that without wire spacer. The effect of gap size on CHF was also investigated in the study. The CHF could reach the values around $100 \%$ higher when the gap size was reduced from $2.0 \mathrm{~mm}$ to $1.1 \mathrm{~mm}$.

The CHF experiment using Freon-12 was done for a hexagonal tight bundle with wire and grid spacers and with $p / d$ of 1.14 [12]. It was reported that the CHF in tight rod bundle with wire spacer was higher than that with grid spacer. The fluid-to-fluid model [13] was used to create the CHF in water condition base on the experimental data in Freon-12 condition.

As the study of thermal-hydraulic performance in tight rod bundle for PWR (pressurized water reactor), the effect of wire spacer on the improvement of CHF was investigated analytically [14].

However, the effect of wire spacer on CHF in tight rod bundle was not investigated sufficiently. Particularly as one of the most important factors that influence the CHF, the effect of a pitch to diameter ratio on CHF was not investigated.

The purpose of the present study is to clarify the CHF behavior in boiling two-phase flow in three-pins tight rod bundle with wire spacer. In particular, the effects of wire spacer and the pitch to diameter ratio on $\mathrm{CHF}$ were investigated experimentally.

\section{Experimental Apparatus and Procedure}

\subsection{Experimental Apparatus}

The experimental apparatus of a water circulation loop has been described in the previous paper [11]. The schematic drawings of the test section are shown in Fig. 1. The flow channel had the triangular shape which was made from three Pyrex glass plate. The triangular flow channel was supported by two polycarbonate plate at both ends.

Three pin-tight rod bundles were made by assembling three heater pins made of stainless steel tubes in the triangular arrangement. The heater pins were $4.57 \mathrm{~mm}$ in outer diameter and $400 \mathrm{~mm}$ in length. The both ends of the heater pin was connected to the copper electrodes by silver soldering. The heater pins were directly heated by Joule-heating and it had an uniform heat flux on the heater pin surface. The experiment can reach the maximum power of $12 \mathrm{~kW}$ and current of $630 \mathrm{~A}$. The wire spacer was electrically insulated from the heater pin by a Teflon tube or Holmal coating so that no heat was generated in the wire.

The pin pitch, $p$, was $5 \mathrm{~mm}$ and $5.4 \mathrm{~mm}$, which corresponded to the pitch to diameter ratio, $p / d$, of 1.10 and 1.18 , respectively. The wire spacer for $p / d=1.18$ was a Teflon tube in outer diameter $d_{w}=0.76 \mathrm{~mm}$ in which a stainless steel wire was inserted, and that for $p / d=1.10$ was a Holmal coated wire in outer diameter $d_{w}=0.4 \mathrm{~mm}$. The reason for the use of Holmal coated wire is to satisfy the gap size of $0.5 \mathrm{~mm}$ in the case of $p / d$ of 1.10 .

A wire spacer was wrapped around each of the heater pin with the axial winding pitch $H=200 \mathrm{~mm}$. 


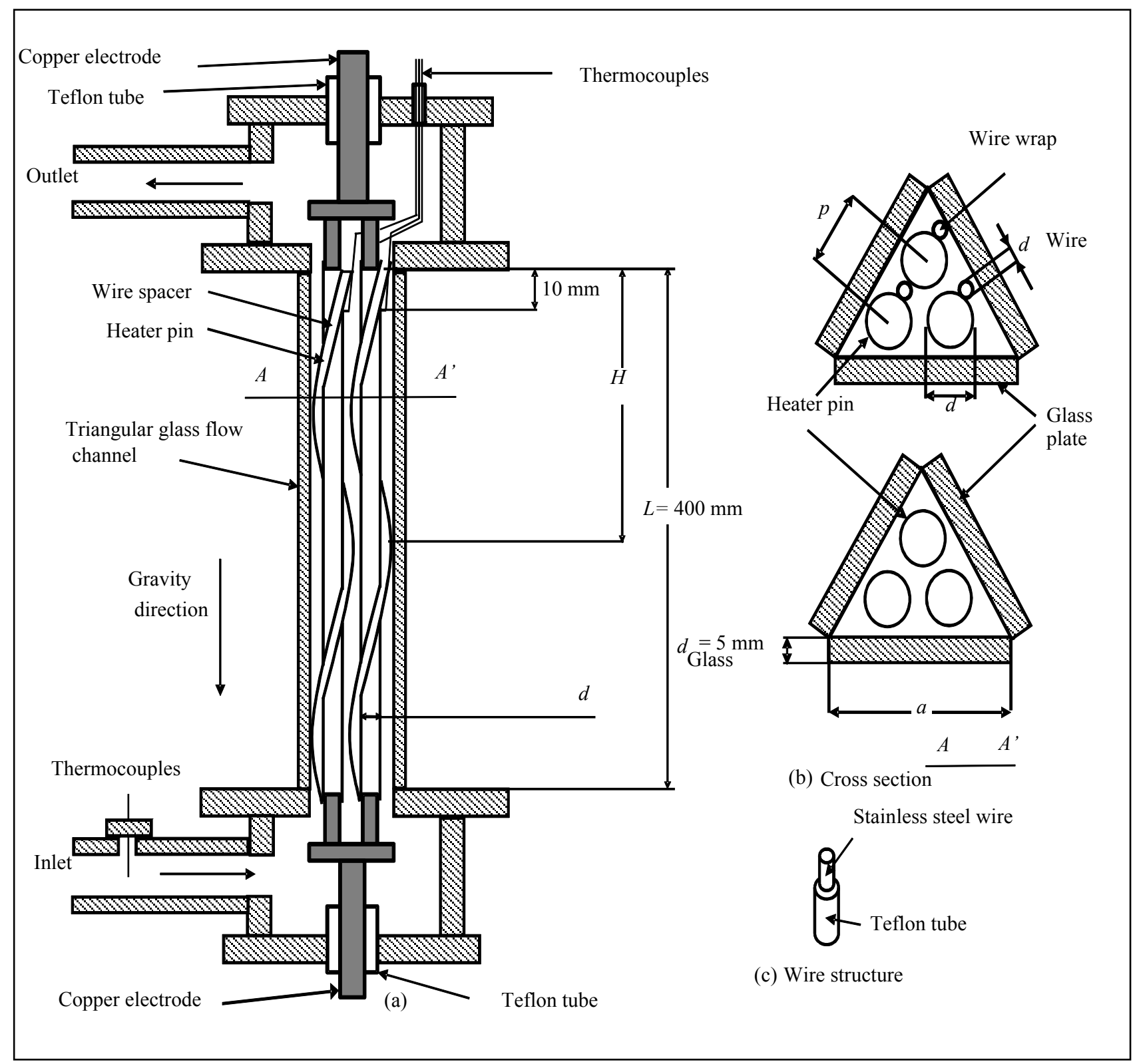

Fig. 1 Test section: (a) test section; (b) cross section of the flow channel with wire and without wire spacer; (c) wire structure.

The value of axial pitch of wire met the requirement of $H / d$ less than 50 which was the upper limit of wire correlation for both CHF and pressure drop [14].

Thermocouple elements were spot-welded on the surface of each heater pin. The surface temperature of the heater pin rapidly rose at the CHF condition. To determine the $\mathrm{CHF}$, the temperature rise at the $\mathrm{CHF}$ condition was detected by thermocouples at the positions $10 \mathrm{~mm}$ upstream from the downstream end of heated length: T1, T2 and T3.
Thin type $\mathrm{K}$ thermocouple elements with the diameter of $100 \mu \mathrm{m}$ were used, so that the thermocouples did not disturb the flow to change the CHF behavior.

\subsection{Experimental Conditions}

The experimental parameters and conditions are given in Table 1.

From the thermal-hydraulic point of view, the effect of a wire spacer on CHF in tight rod bundle at constant 
Table 1 Experimental conditions.

\begin{tabular}{lllll}
\hline \multirow{2}{*}{ Parameter } & Run. 1 & Run. 2 & Run. 3 Run. 4 \\
\cline { 2 - 5 } & Wire & No wire Wire & Wire \\
\hline Pitch to diameter ratio, $p / d$ & 1.18 & & 1.10 \\
Wire diameter, $d_{w}(\mathrm{~mm})$ & 0.76 & - & 0.76 & 0.4 \\
Wire axial pitch, $H(\mathrm{~mm})$ & 200 & - & 200 & \\
Mass flux, $G\left(\mathrm{~kg} /\left(\mathrm{m}^{2} \cdot \mathrm{s}\right)\right)$ & 435 & - & \\
Mass flow rate, $W(\mathrm{~kg} / \mathrm{s})$ & - & & 0.0208 \\
Hydraulic diameter of flow & 0.0029 & 0.0032 & 0.0029 & 0.0021 \\
channel, $D_{h y}(\mathrm{~m})$ & & & & \\
Outer diameter of & 4.57 & & \\
heater pin, $d(\mathrm{~mm})$ & 0.1 & & \\
Pressure, $P(\mathrm{MPa})$ & $343-365$ & \\
Inlet temperature $(\mathrm{K})$ & &
\end{tabular}

mass flux is interesting. Thus, the CHF experiments for both cases of heater pin with and without a wire spacer were conducted under the same mass flux condition. On the other hand, from the viewpoint of the design of the practical reactor, it is important to know how the coolability changes with the change of core tightness under constant mass flow rate. Thus, the experiments were conducted for two different values of $p / d$ at the same flow rate condition.

\section{Results}

\subsection{Effect of Wire Spacer}

Fig. 2 shows the result of CHF with and without wire spacer. The CHF values with wire spacer were higher than that without wire spacer. The difference in $\mathrm{CHF}$ value was larger at the quality region from $x_{\text {local }}=-0.06$ to 0 than at the quality region from $x_{\text {local }}=0$ to 0.02 .

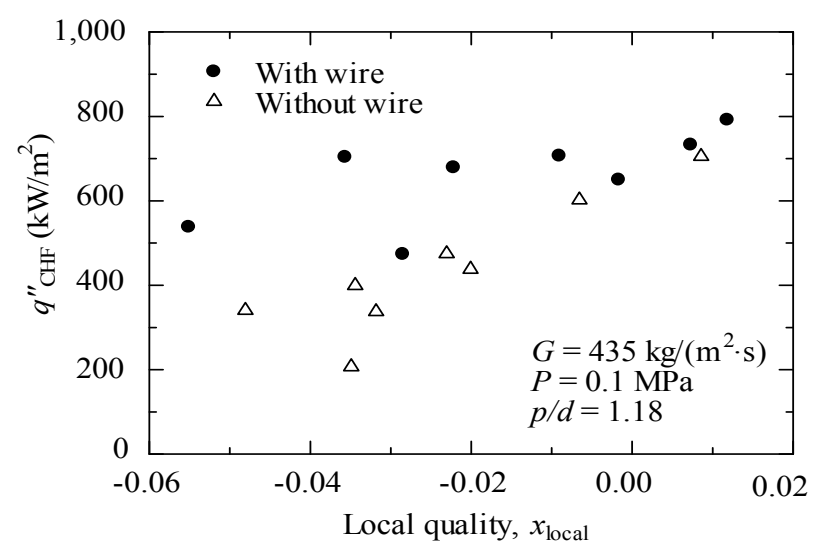

Fig. 2 Critical heat flux in bundle with and without wire spacer.
The CHF was enhanced by up to $50 \%$ with wire spacer compared with it without wire spacer under the constant mass flux condition. The enhancement was more significant at the low quality region. Therefore, the coolability in tight lattice core could be optimized by using wire spacer.

\subsection{Effect of Pitch to Diameter Ratio}

Fig. 3 shows the results of CHF values for three-pin bundle experiment with $p / d=1.10$ and 1.18 under the same mass flux condition. It is found that, the CHF values have a similar tendency even with different $p / d$. Additionally, the CHF data with $p / d=1.10$ was slightly lower than that in the case of $p / d=1.18$ under the same mass flux condition.

The comparison of CHF between two different values of $p / d$ under constant mass flow rate is shown in Fig. 4.

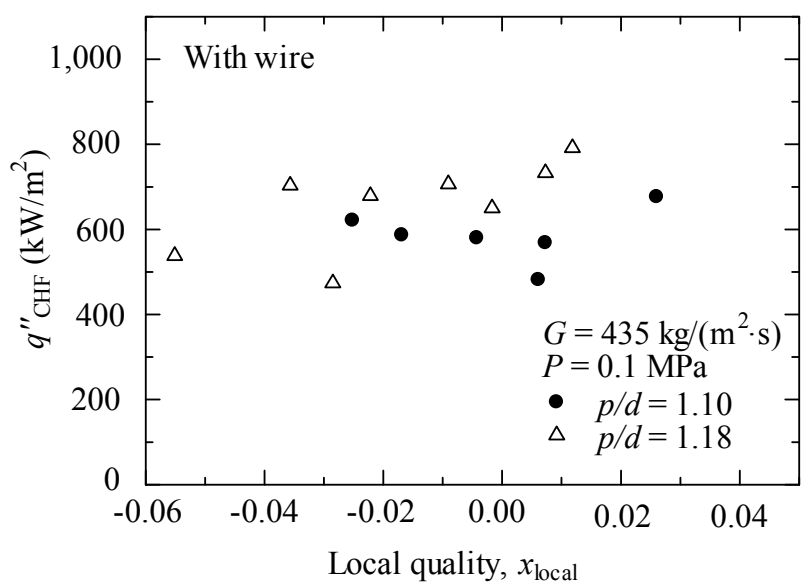

Fig. $3 \mathrm{CHF}$ of different values of $p / d$ under the constant mass flux condition.

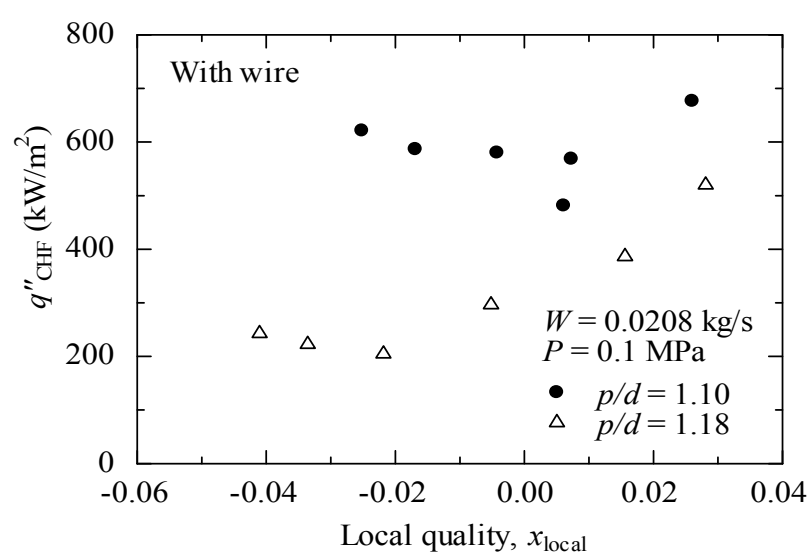

Fig. 4 CHF of difference values of $p / d$ with the same flow rate condition. 
It can be seen that, the CHF values for $p / d=1.10$ were much higher than that for $p / d=1.18$ under the same mass flow rate condition particularly in lower range of $x_{\text {local }}$.

\subsection{Axial CHF Position}

Figs. 5 and 6 show the position where CHF occur red in all the experiment. Fig. 5 shows that the positions of most of CHF at $p / d=1.18$ and $G=280 \mathrm{~kg} /\left(\mathrm{m}^{2} \cdot \mathrm{s}\right)$ were located in the downstream region of the flow channel. However, when the mass flux was increased from $280 \mathrm{~kg} /\left(\mathrm{m}^{2} \cdot \mathrm{s}\right)$ to $435 \mathrm{~kg} /\left(\mathrm{m}^{2} \cdot \mathrm{s}\right)$, the CHF occurred in the middle of the heater pin. Fig. 6 shows that, under constant mass flux condition of $W=435 \mathrm{~kg} /\left(\mathrm{m}^{2} \cdot \mathrm{s}\right)$, CHF occurred at nearly the same position at $p / d=1.10$ and 1.8 .

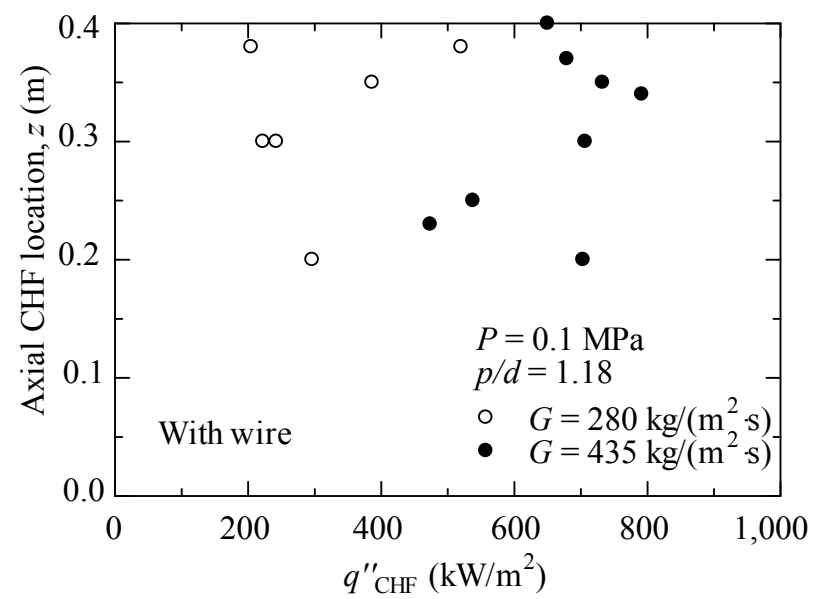

Fig. 5 CHF position along the heated length with the effect of mass flux.

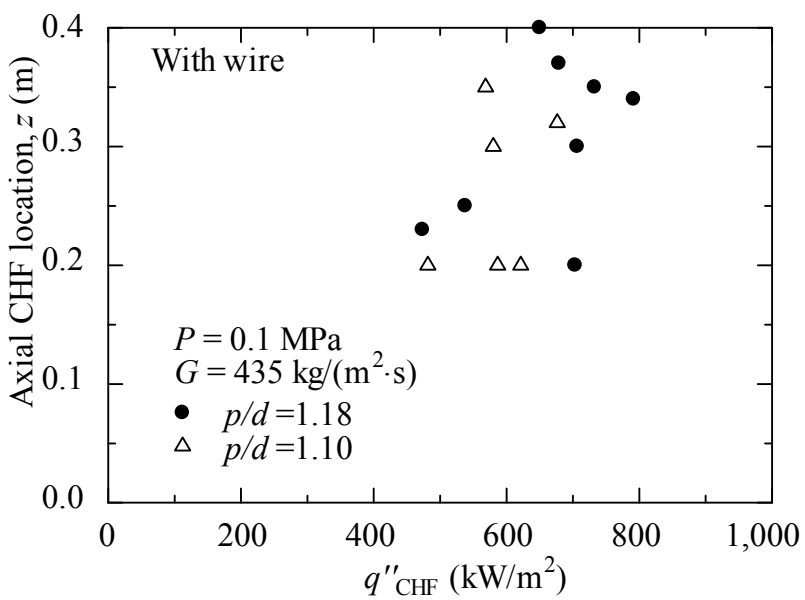

Fig. 6 CHF position along the heated length with the effect of $p / d$.

\section{Discussion}

It was revealed that the existence of wire spacer enhanced the CHF from the result in Fig. 2. The reason for the enhancement can be explained by two parts based on the local vapor quality region. In the range of the quality from -0.06 to 0 , the enhancement of CHF was very clear, which was possibly caused by the increase of disturbance by wire spacer. In the low quality region, the turbulent mixing caused by the disturbance became higher, which enhanced the bubble removal from the heated surfaces. As a result, CHF increased. The existence of the wire spacer induced a spiral flow, which increased coolant velocity. Therefore, the CHF increased in comparison with the case of straight flow.

Besides, in the range of positive local vapor quality, the CHF was nearly the same in the cases of bundle pins with wire and without wire spacer. It has been known that, the liquid film flow becomes thinner compared with it in the low quality region in the high quality region. In the condition of the thin liquid film flow, the wire spacer may break the liquid film flow, and consequently the dry-out more easily occurs. Since the boiling heat transfer rate becomes higher in the high quality region than in low quality region, the disturbances of the bubbles become higher and tend to break the liquid film, which leads to the decrease of CHF values.

The effect of $p / d$ on CHF value was investigated both under constant mass flux conditions and at constant mass flow rate conditions.

In the case of constant mass flux conditions, it was found in Fig. 3 that, the CHF values for $p / d=1.10$ were nearly the same as those for $p / d=1.18$. However, the difference became larger in the region of higher quality $x>0.01$, that is, the CHF values for $p / d=1.18$ were higher than those for $p / d=1.10$. The reason for this result is related to the geometric factorial. For $p / d=$ 1.10 , the flow area is smaller than that for $p / d=1.18$. Hence, in the flow channel with $p / d=1.10$, the bubbles coalesced with each other into larger bubbles more 
easily, and covered the heated surface, and as a result hinder the cooling of heater pin by the liquid film, which lead to lower CHF values for $p / d=1.10$ compared with those for $p / d=1.18$.

In contrast, it was shown under constant mass flow rate conditions in Fig. 4 that, the CHF values for $p / d=$ 1.10 were higher than those for $p / d=1.18$. It can be explained by the increase of mass flux. With the same flow rate condition, the flow channel which has a smaller value of $p / d$ would have a smaller flow area, which leads to a higher mass flux. Therefore, the coolant velocity in case of $p / d=1.10$ was higher than that in the case of $p / d=1.18$ at the same flow rate condition. Therefore, the coolability was enhanced by tighter core lattice under the constant mass flow rate condition, which turns to a higher CHF values.

The result of the measured position at which CHF occurred along the heated length suggests that CHF mechanism changed with changing the value of $p / d$ and mass flux. In the case of the lowest mass flux of $280 \mathrm{~kg} /\left(\mathrm{m}^{2} \cdot \mathrm{s}\right)$ in the flow channel with $p / d=1.18$, the CHF positions were mostly in the downstream region of the flow channel, which suggested the occurrence of liquid film dryout along the heater pin. On the other hand, at higher mass flux, $435 \mathrm{~kg} /\left(\mathrm{m}^{2} \cdot \mathrm{s}\right)$, CHF positions shifted to the middle of the flow channel, which suggested the DNB (departure from nucleate boiling) phenomenon. In short words, the CHF mechanism changed from the liquid film dryout phenomenon to DNB phenomenon with an increase of mass flux.

It is shown in Fig. 6 that, under the same mass flux condition, the CHF positions were nearly the same even with two different values of $p / d$. It can be concluded that, the CHF position, or CHF mechanism, was just dependent on mass flux.

\section{Conclusions}

Critical heat flux in boiling water flow in a tight rod bundle was investigated experimentally for a three-pin bundle with and without wire spacers. Two different values of pitch to diameter ratio were chosen: 1.10 and
1.18. The conclusions are as follows:

(1) The CHF was enhanced by up to $50 \%$ with wire spacer compared with it without wire spacer under constant mass flux condition. The enhancement was more significant at the low quality region. Thus, the coolability in tight lattice core could be optimized by using wire spacer.

(2) Under constant flow rate conditions, the CHF values increased by up to $150 \%$ by decreasing the pitch to diameter ration from 1.18 to 1.10 .

(3) Under constant mass flux conditions, the tendency of CHF values did not change even with different values of $p / d$. The CHF decreased by around $5 \%$ by changing the $p / d$ from 1.18 to 1.10 .

(4) The positions of CHF at $p / d=1.18$ and low mass flux were located in the downstream region of the flow channel. However, when the mass flux was increased, the CHF occurred in the middle of the heater pin. Under constant mass flux condition, CHF occurred at nearly the same position for both of $p / d=1.10$ and 1.8.

\section{Acknowledgments}

The study was supported by Hitachi Nuclear Scholarship project. The authors would like to give the thanks to Dr. Masatoshi Kondo for his discussion and to Mr. Naoyuki Tsuruoka and Mr. Shoji Matsui for their assistance in the technical work.

\section{References}

[1] Sidik, P., Takaki, N., and Sekimoto, H. 2006. "Impact of Different Moderator Ratios with Light and Heavy Water Cooled Reactor in Equilibrium States." Annals of Nuclear Energy 33 (7): 561-72.

[2] Uchikawa, S., Okubo, T., Kugo, T., Akie, H., Takeda, R., Nakano, Y., Ohnuki, A., and Iwamura, T. 2006. "Conceptual Design of Innovative Water Reactor for Flexible Fuel Cycle (FLWR) and Its Recycle Characteristics." Journal of Nuclear Science and Technology 44 (3): 277-84.

[3] Sidik, P., Takaki, N., and Sekimoto, H. 2008. "Preliminary Study on Feasibility of Large and Small Water Cooled Thorium Breeder Reactor in Equilibrium Sates." Progress in Nuclear Energy 50 (2-6): 320-4.

[4] Ohnuki, A., Takase, K., Kureta, M., Yoshida, H., Tamai, 
H., Liu, W., Nakatsuka, T., Misawa, T., and Akimoto, H. 2005. "Master Plan and Current Status for Feasibility Study on Thermal/Hydraulic Performance of Reduced-Moderation Water Reactor." Presented at the International Conference on Nuclear Energy System for Future Generation and Global Sustainability (GLOBAL 2005), Nagahama, Japan.

[5] Cheng, X., 2005. "Experimental Studies on Critical Heat Flux in Vertical Tight 37-Rod Bundles Using Freon-12." International Journal of Multiphase Flow 31 (10-11): 1198-219.

[6] Kureta, M., Tamai, H., Ohnuki, A., Sato, T., Liu, W., and Akimoto, H. 2006. "Critical Power Experiment with a Tight-Lattice 37-Rod Bundle.” Journal of Nuclear Science and Technology 43 (2): 198-205.

[7] Cheng, X., Erbacher, F. J., and Müller, U. 1997. "Critical Heat Flux in Uniformly Heated Vertical Tubes." International Journal of Heat Mass Transfer 40 (12): 2929-39.

[8] Liu, W., Kureta, M., and Ohnuki, A., 2004. "Critical Power in 7-Rod Tight Lattice Bundle.” JSME Int. J. B 44 (2): 299-305.

[9] Nakatsuka, T., Tamai, H., and Akimoto, H. 2005.
"Subchannel Analysis of 37-Rod Tight-Lattice Bundle Experiments for Reduced-Moderation Water Reactor." Presented at the International Conference on Nuclear Energy System for Future Generation and Global Sustainability (GLOBAL 2005), Tsukuba, Japan.

[10] Tamai, H., Kureta, M., Liu, W., Sato, T., Ohnuki, A., and Akimoto, H. 2007. "Gap Width Effect on Critical Power Based on Tight-Lattice 37-Rod Bundle Experiments." Journal of Nuclear Science and Technology 44 (1): 54-63.

[11] Le, D., and Takahashi, M., 2015. "Improvement of Critical Heat Flux by Wire Spacer." Journal of Energy and Power Engineering 9 (10): 844-51.

[12] Cheng, X., and Müller, U. 1998. "Critical Heat Flux and Turbulent Mixing in Hexagonal Tight Rod Bundles." International Journal of Multiphase Flow 24 (8): 1245-63.

[13] Courtaud, M., Deruaz, R., and D'Aillon, L. G. 1988. “The French Thermal-Hydraulic Program Addressing the Requirements of the Future Pressurized Water Reactors." Nucl. Technol. 80 (1): 73-82.

[14] Diller, P., Todreas, N., and Hejzlar, P. 2009. "Thermal-Hydraulic Analysis for Wire-Wrapped PWR Cores." Nuclear Engineering and Design 239 (8): 1461-70. 